ATMOSPHERIC SCIENCE

\section{Aerosols suppress hurricanes}

Aerosol particles from human activities could have lowered the number of tropical storms over the Atlantic Ocean during the twentieth century.

Natural aerosols such as dust particles are thought to influence hurricane activity, but the effects of anthropogenic aerosols are unclear. A team led by Nick Dunstone at the Met Office Hadley Centre in Exeter, UK, modelled the frequency of North Atlantic tropical storms with simulations that either incorporated or excluded changes in man-made aerosols. The model suggests that as levels of anthropogenic aerosols increased in the earlier part of the century, tropical storm activity dropped; aerosol declines at the end of the century increased storms.

The authors attribute this to the effect of aerosols on clouds. By brightening clouds and causing them to stick around for longer, aerosols cool surface temperatures and shift circulation patterns in a way that suppresses hurricanes. Nature Geosci. http://dx.doi. org/10.1038/ngeo1854 (2013)

\section{MATERIALS SCIENCE}

\section{Droplets move to softer substrates}

Liquid droplets dripped onto a silicone gel will move from thin, stiff regions to thick, springy ones.

This intriguing behaviour, reported by Eric Dufresne at Yale University in New Haven, Connecticut, and his colleagues, occurs because

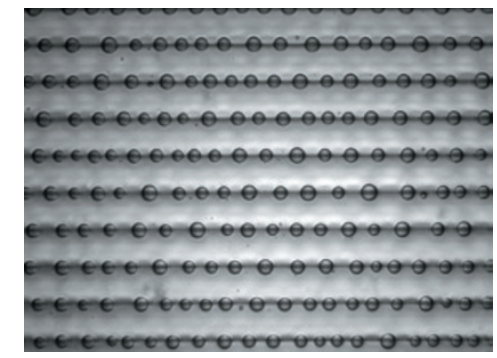

of the physics of surface tension. A droplet tends to spread out over a thick, deformable surface, but rears up into a spherical shape at thinner, stiffer places. A similar phenomenon occurs in biology, but in reverse: cells tend to move to stiffer parts of a substrate, a process called durotaxis. The biological movement is thought to involve the cell actively sensing its environment and using actin-myosin fibres to control locomotion. The liquid durotaxis can be used to generate patterns of droplets (pictured) without chemical or thermal gradients and might be useful in microfluidics, the authors speculate.

Proc. Natl Acad. Sci. USA http://dx.doi.org/10.1073/ pnas.1307122110 (2013)

\section{APPLIED PHYSICS}

\section{Metamaterial wall amplifies sound}

Sound waves can squeeze through holes smaller than their wavelength in a specially fabricated wall.

Metamaterials are artificial materials precisely engineered from metals or plastics to have structures that manipulate sound or light waves. Such materials have already been used to direct light waves through seemingly impassible openings. To accomplish such 'extraordinary transmission' with sound, Sam Lee at Yonsei University in Seoul, South Korea, and his colleagues stretched pieces of plastic film across tiny perforations in a thin metal plate. Incoming sound

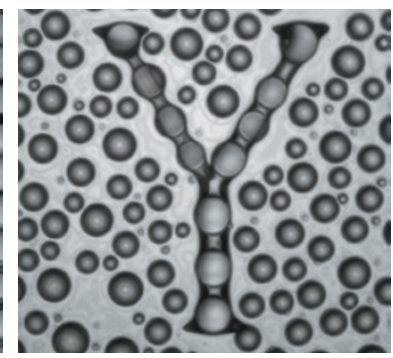

COMMUNITY CHOICE

The most viewed papers in science

\title{
Comprehensive fly library
}

\section{HIGHLY READ \\ on dev.biologists. org in May}

A method that can systematically generate fruitflies to overexpress particular genes will help researchers to explore gene function in the model organism.

Konrad Basler at the University of Zurich, Switzerland, and his colleagues developed a scalable method to overexpress genes at known sites in the genome of the fruitfly Drosophila. They coupled a system that allows controlled gene expression with one that allows site-specific integration of a newly introduced gene. The researchers used the technology to establish a library of 1,149 fly strains. The approach could be used to efficiently explore effects of overexpression in a comprehensive set of fly genes and to complement experiments with knockout flies, in which particular genes are disabled or deleted, the authors say.

Development 140, 2434-2442 (2013)

waves of a selected frequency resonated with the film, causing air to flow as if it were massless and funnel as much as $97 \%$ of the sound through the holes. The sound was intensified within the holes by a factor of up to 5,700 , and thus could be used in sensitive detectors, the researchers suggest.

Phys. Rev. Lett. 110, 244302 (2013)

\section{Enzyme duo elicit nerve branching}

A pair of enzymes control where synapses form in neurons by guiding the transport of energyproducing organelles called mitochondria.

A team led by Franck Polleux at the Scripps Research Institute in La Jolla, California, identified two enzymes that are required for axons (the long messagetransmitting stalks of neurons) to branch and form synapses with other neurons. When these enzymes were overexpressed in neurons, mitochondria moving down the axon, along microtubules, were immobilized at the

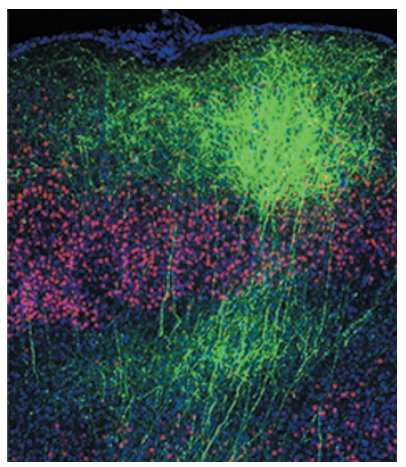

point where axons would form synapses. Higher levels of these enzymes boosted axon branching (pictured), whereas lower levels reduced it.

The researchers suggest that the two enzymes work together to tell mitochondria where to stop and thus where synapses will form. Mitochondrial transport could factor in the development of a wide range of disorders, including autism, through its effects on synapse formation, the authors say.

Cell http://dx.doi.org/10.1016/j. cell.2013.05.021 (2013)

\section{$\rightarrow$ NATURE.COM}

For the latest research published by Naturevisit:

www.nature.com/latestresearch 